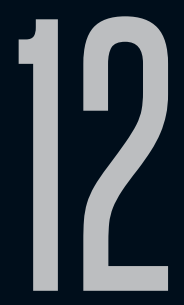

\title{
O MAGO ANTI-HERÓI DE ERIC NOVELLO ${ }^{1}$
}

Ana Carolina Lazzari Chiovatto (USP/FAPESP)

Recebido em 25 jun 2018. Ana Carolina Lazzari Chiovatto é Doutoranda em Aprovado em 25 jul 2018. Estudos Linguísticos e Literários em Inglês pela Universidade de São Paulo e mestra na mesma área (conclusão em 2017), com período sanduíche de seis meses na Universidade do Porto (1ํㅗ semestre de 2016). Possui graduação em Comunicação Social - Publicidade e Propaganda pela Faculdade das Américas (2012). É tradutora literária de língua inglesa e possui experiência na área de Comunicação e na área editorial, com revisão de tradução e preparação de textos. Além disso, é escritora e possui contos publicados.

Resumo: Tradicionalmente, na fantasia, a figura do mago associa-se à do ancião sábio que direciona a aventura do herói. Seu papel, desde o Merlin medieval até importantes releituras contemporâneas, como Gandalf, em O Senhor dos Anéis (1955), de J.R.R. Tolkien (1892-1973), ou Alvo Dumbledore, em Harry Potter (1997-2007), de J.K. Rowling (1965) pode conter pequenas ambivalências, mas, em geral, porta-se como a figura de autoridade dotada dos conhecimentos necessários para possibilitar a "jornada do herói", cuja preocupação costuma atuar na esfera do coletivo e do bem comum. No entanto, o mago também existe enquanto anti-herói, seguindo uma tradição bem mais 
recente, própria da literatura insólita contemporânea. Neste artigo, analisaremos o mago exorcista Tiago Boanerges, do escritor carioca Eric Novello (1978), personagem do romance Exorcismos, Amores e uma Dose de Blues (2014), em contraste com outros magos dessas duas tradições, pois a personagem de Novello apresenta particularidades em sua trajetória narrativa que o enquadram no grande arquétipo do anti-herói, guardando apenas uma relação distante com os grandes magos da literatura de fantasia ocidental e, ao mesmo tempo, identificando-se com seus pares em obras anglófonas contemporâneas, como John Constantine, personagem da aclamada série de HQs Hellblazer, e Harry Dresden, de Jim Butcher, na série de romances The Dresden Files.

Palavras-chave: Figura do mago; Anti-herói; Literatura brasileira contemporânea; Fantasia urbana; Alta fantasia.

Abstract: Traditionally, in fantasy, the wizard figure is related to the elderly sage who directs the hero towards adventure. His role, from medieval Merlin to important contemporary rereadings, such as Gandalf the Grey, in The Lord of the Rings, by J.R.R. Tolkien, or Albus Dumbledore, in Harry Potter, by J.K. Rowling, may present a few ambivalent traces, but he is, in general, the authority figure who has the necessary knowledge to the hero's journey, whose major interest is usually the community and the common good. Nevertheless, the wizard also exists as an anti-hero figure, according to a much more recent tradition, typical in the contemporary literature of fantasy. In this paper, I analyse Tiago Boanerges, an exorcist wizard, in Exorcismos, Amores e Uma Dose de Blues (2014), by Eric Novello (1978), in comparison to wizards from both traditions. Novello's lead character displays some particularities along the narrative, presenting only a distant relation to the great wizards of Western literature, while identifying with his 
peers from contemporary anglophone works, like Hellblazer's John Constantine, and Jim Butcher's Harry Dresden, in The Dresden Files book series.

Keywords: Wizard figure; Anti-hero; Contemporary Brazilian literature; Urban fantasy; High fantasy.

\section{O MAGO MERLIN E SEUS HERDEIROS}

A figura do mago é, tradicionalmente, a do sábio ancião, imagem que em muito se deve à personagem histórico-mítica de Merlin, híbrida de diversas origens conjugadas na figura conhecida nos dias de hoje. Por mais que divirjam, as várias figuras de Merlin unificam-se "na condição profética, característica com a qual ficaria marcado o personagem na literatura arturiana" (PEREIRA; MATIAS, 2013, p.65).

Nos manuscritos medievais nos quais primeiro apareceu, a personagem apresenta uma ambiguidade logo esquecida em seus herdeiros contemporâneos mais imediatos e depois retomada na figura do mago anti-herói. Como nos dizem duas historiadoras,

O Merlin de [Robert de] Boron é o filho de um íncubo, nascido de um plano diabólico arquitetado nas entranhas do inferno, como o autor faz enunciar nas palavras do próprio mago: Je suis fils d'un diable. Acentua-se, entretanto, em Boron, a perspectiva de que o plano diabólico de extensão do mal sobre a terra foi frustrado pela misericordiosa intervenção de Deus, que toma o mago a seu serviço e concede-lhe a graça da previsão do futuro. (PEREIRA; MATIAS, 2013, p.66)

A origem diabólica definiria instantaneamente Merlin como um agente do Mal, em particular se considerarmos o contexto históricosocial no medievo dominado pela Igreja Católica. A magia, dentro do cristianismo, só pode existir no plano terreno por ação do Diabo 
(SPRENGER; KRAMER, 2011). No entanto, a suposta decisão de Deus de clamar para si seu poder e lhe conceder a clarividência mitiga um pouco a carga disfórica atribuída à magia. Na Alta Idade Média, embora a Igreja negasse, ainda era difundida a ideia de profecias divinas - mais tarde, na Europa sob a égide da Inquisição, até mesmo esse dito dom será demonizado (GINZBURG, 2012).

Porém, não só a capacidade clarividente de Merlin permanece no imaginário: antes disso, é sua imagem de idoso barbudo, embora, nas obras que primeiro registram seu aparecimento, não haja descrições físicas (RINALDI, 2016, p.5). Entretanto, já na época, em meados do século XII, grande parte das culturas europeias ocidentais associava a idade avançada à sabedoria, este que é o principal traço distintivo do mago Merlin, "imagem consubstanciada pelas iluminuras dos manuscritos que retratam a personagem de barba e vestido de uma túnica com carapuço azul" (RINALDI, 2016, p.7).

Sua sabedoria consiste numa espécie de capacidade mágica também, refletida em sua precocidade para aprender a falar. Isso é especialmente importante num contexto mágico, pois a palavra, no mais das vezes, é a materialidade capaz de dar vazão a um feitiço. Além disso, "sua inteligência e seus conhecimentos ultrapassam os limites do esperado para um mortal comum" (PEREIRA; MATIAS, 2013, p.68), algo que ele, de fato, não é.

Merlin, é claro, é uma figura instável no imaginário, por causa da criação coletiva. Atualmente, sua versão mais conhecida é a de Sir Thomas Malory (1415-1471) em seu A Morte de Arthur (1485). Em meio às inúmeras releituras, ele sofreu múltiplas transformações, tornando-se um idoso brincalhão, sábio e bondoso, na série $O$ 
único e eterno rei (1958-1977), de T.H. White; um herói, ainda um mago, na série de romances Merlin (1970-1995), de Mary Stewart; um druida religioso, na trilogia As crônicas de Artur, de Bernard Cornwell (1995-1997), entre outros.

Sua face mais conhecida, já na contemporaneidade, é relida no mago Gandalf, de J.R.R. Tolkien, em O Senhor dos Anéis, é antes de tudo um sábio na forma de um ancião. À semelhança de Merlin, ele é "um velho com um cajado [...] um chapéu azul, alto e pontudo, uma capa cinzenta comprida, um cachecol prateado sobre o qual sua longa barba branca caía até abaixo da cintura, e imensas botas pretas" (TOLKIEN, 2001, p.4). Além disso, o poder de Gandalf também advém do domínio da palavra, de maneira mais direta do que se vê nas múltiplas versões de Merlin, através de feitiços sussurrados ou entoados como cânticos. O conhecimento de muitas línguas da Terra Média, o universo ficcional onde se passa a narrativa de Tolkien, também é uma das marcas do mago Gandalf.

Contudo, em vez de possuir origens diabólicas como Merlin, Gandalf é uma forma encarnada de uma divindade da mitologia tolkieniana. Essa diferença substancial não apaga de Gandalf um pouco da dubiedade da origem merliana; suas intenções são questionadas em alguns momentos de O Senhor dos Anéis (TOLKIEN, 2001). Mesmo assim, sua figura possui, de certo modo, um caráter messiânico: uma das referências de Tolkien à Bíblia "é o fato de que Gandalf - assim como Jesus - foi designado para orientar os povos e não para obrigá-los a seguir o caminho ao qual apontava" (STAINLE, 2016, p.86).

O fato de o mago ser um emissário do divino serve tanto para estabelecer seu papel no eixo eufórico da narrativa quanto 
para limitar a esfera de seu poder. É uma tradição judaico-cristã o divino refrear-se para permitir o livre arbítrio humano atuar. Com isso, permite que a jornada heroica aconteça. Se a magia pudesse resolver qualquer situação adversa, não haveria trama. Assim, apesar das origens praticamente opostas, "la función principal de Gandalf en El Señor de los Anillos es la misma que la de Merlín siglos atrás: supervisar los quehaceres humanos [...], y sus consejos son tenidos más como proposiciones que como imposiciones" (REDONDO, 2007, p.154).

No papel de conselheiros, os magos constituem figura de autoridade para as personagens tanto quanto regulam o ritmo da narrativa. Afinal, "Gandalf é quem controla o quanto cada uma das personagens sabe" (STAINLE, 2016, p.88), e o saber é uma das competências necessárias ao sujeito do fazer (costumeiramente o protagonista).

Na esteira de Gandalf, temos Alvo Dumbledore, o mentor de Harry Potter na série homônima de livros assinada por J.K. Rowling. Com a mesma barba branca comprida, chapéu pontiagudo e túnica, além da imagem física, Dumbledore assemelha-se a seu antecessor também nos papéis por ele representados na narrativa, bem como pela personalidade, ora misteriosa, ora bem-humorada, de um idoso bondoso e pacífico, mas, ao mesmo tempo, grande guerreiro. Embora seja tão humano quanto o protagonista - sem origem divina ou diabólica, num mundo onde a magia é amplamente utilizada - , o velho mago possui mais sabedoria e conhecimento do que as demais personagens, tanto por sua idade magicamente avançada (superando bastante a expectativa de vida humana, tal qual seus antecessores) quanto por sua inegável erudição e, em 
consequência, manipula magia de modo mais refinado que os demais bruxos.

Da mesma maneira que Gandalf escolhe quais informações revelar e quais ocultar do protagonista, conduzindo a narrativa. No entanto, ao longo da série, essa característica ganha contornos ambivalentes, pois em nome do "bem maior" Dumbledore não se abstém de sacrificar indivíduos sem a expressa anuência destes, algo que o mago de Tolkien jamais faria. Assim sendo, reaproxima-se do Merlin cristalizado no imaginário ocidental por sua ambiguidade, mesmo se direcionada de modo diverso à do mago arturiano. As ações deste último, por mais "diabólicas" que sejam pelo simples uso da magia, não se voltam contra o herói, enquanto Dumbledore oculta a necessidade do sacrifício da vida de Harry no confronto final. Como os anti-heróis dos quais falaremos, ele segue mais seu próprio compasso moral do que regras preestabelecidas socialmente. Nada tem de diabólico, como Merlin em sua origem, porém parece mais maquiavélico conforme se descobre o quanto se desvia da figura paterna que julgávamos ser nos primeiros livros.

Não obstante suas diferenças, Merlin, Gandalf e Dumbledore atuam como destinador dos sujeitos, isto é, quem direciona os protagonistas em suas aventuras, majoritariamente no papel de conselheiro. Não são o herói, mas um suporte para o herói, alguém a entrar em cena e sair de cena em momentos estratégicos para que a jornada possa existir nos termos narrativos descritos por Joseph Campbell em O Herói de Mil Faces (1989).

No fim do século XX e início do XXI, outro tipo de mago floresce, na ascendente figura do anti-herói, desempenhando o papel de 
protagonista. Para isso, ele costuma ganhar feições mais humanas, apesar de seus poderes mágicos.

Passemos, pois, a observar esse movimento no caso de alguns personagens de obras anglófonas para balizar a análise do objeto do presente artigo, isto é, o mago exorcista Tiago Boanerges, de Eric Novello, em Amores, Exorcismos e Uma Dose de Blues.

\section{O MAGO COMO ANTI-HERÓI}

O termo "anti-herói" adentrou a literatura com Dostoievski, embora o tipo de personagem por ele designado possa ser encontrado desde o teatro grego, e tenha se difundido melhor a partir da segunda metade do século XX (KADiROĞLU, 2012, p.1), após as guerras mundiais, quando se exacerbaram as mudanças começadas no século XIX, nomeadamente uma ascensão da individualidade em detrimento do coletivo. Ao mesmo tempo, havia certo sentimento de impotência, a ideia de que uma pessoa sozinha não poderia fazer grande diferença dentro do sistema (KADiROĞLU, 2012, p.1).

Nessa conjuntura,

Faltam aos anti-heróis modernos grandeza, graça, poder e sucesso social. Quando as condições de crise externa se confirmaram, os escritores modernistas levaram seus anti-heróis ao domínio do doméstico ou à privacidade da mente. Astradur Eysteinsson fala de um moderno anti-herói introvertido "em quem uma consciência aguçada e o isolamento e a paralisia sociais andam de mãos dadas, assim como a exaltação da individualidade e seu apagamento". Theodore Ziolkowski insinua a indecisão dos antiheróis modernos, generalizando-a para sugerir que os momentos de hesitação dos heróis de grandes 
obras mundiais, da antiguidade ao presente, podem ser vistos como "exemplos de crises nas culturas que os engendraram". Mudanças nos sistemas de valor e nos ambientes culturais, afirma Ziolkowski, formam os heróis encontrados na literatura: "se olharmos além da psicologia das personagens, para os mitos culturais que as geram e alimentam, os 'heróis' e 'heroínas' que imaginamos inevitavelmente podem ser lidos como uma projeção do esforço de cada era em confrontar os medos e sonhos coletivos da humanidade. Uma sociedade fragmentada - despedaçada pela guerra, por valores conflitantes e por diferentes aspectos da modernidade - produz seu próprio modelo heroico: anti-heróis doentes, antissociais e introspectivos, cuja salvação é individualista em meio à desordem social e cultural ${ }^{2}$. (NEIMNEH, 2013, p.p.77-78)

Embora o pesquisador aqui se refira em especial a obras de cunho realista, analisando detidamente anti-heróis de Joyce e Beckett, podemos ler sob essa ótica também obras de fantasia, com uma tendência a certa atmosfera noir (CAMPOS, 2016, p.p.30-38), cujo pessimismo do cenário reflete a modernidade apontada acima.

Ao anti-herói, são permitidos o fracasso e a frustração, a impotência frente a forças maiores, bem como certa astúcia, malícia e mesmo desonestidade. Enquanto o herói arquetípico descrito por Campbell "passa por todo o processo de partida, iniciação e retorno, ao longo do qual enfrenta obstáculos e sai triunfante, o antiherói moderno faz uma jornada interior, desprovida da grandeza mítica" (NEIMNEH, 2013, p.78-79). A anterior aventura mundo afora acontece num cenário corriqueiro; "a iniciação vira uma lição

2 Salvo quando indicado o tradutor, todas as traduções são nossas. 
que a personagem aprende acerca de suas próprias fraquezas e limitações, e o triunfo do retorno pode ser meramente sobreviver num mundo caótico, demonstrando a capacidade do protagonista de se adaptar às circunstâncias cambiantes" (NEIMNEH, 2013, p.7879), senão adversas.

O anti-herói, em obras ditas realistas, ainda é dotado de certo tipo de heroísmo, mas numa escala menor, numa esfera mais circunscrita ao pessoal. Na literatura fantástica em sentido lato, e especialmente na fantasia, o nível pessoal/individual com frequência é confrontado por um obstáculo de proporções maiores e a aventura heroica aparece em moldes diferentes das de Campbell, mesclando a grandeza mítica das velhas lutas do Bem contra o Mal com uma jornada de autodescoberta e engrandecimento na esfera do indivíduo.

Enquanto em obras anteriores é frequente o embate entre o coletivo e o individual e a moral é direcionada de modo a priorizar o coletivo, na figura do anti-herói os contornos desse embate vão se tornando cada vez mais nuançados. Segundo Hunter Burnett, a propósito dos estudos desenvolvidos em 1971 pelo psicólogo estadunidense Lawrence Kohlberg, as pessoas conseguem racionalizar a moralidade em três níveis:

O nível pré-convencional consiste em indivíduos que se comportam de acordo com o que lhes traz mais benefícios. As pessoas nesse nível de moralidade determinam o que é bom ou mau pelo quanto suas necessidades são satisfeitas e, às vezes, as necessidades de terceiros. O segundo nível, onde a maioria da população está, é o convencional. Neste, os indivíduos defendem as regras e leis da comunidade. Pessoas nesse nível identificam-se 
com um grupo em especial e defendem e seguem as leis, independentemente de quais sejam. O terceiro e último, que abarca quase todos os anti-heróis, é o nível pós-convencional. Neste, indivíduos pensantes possuem valores e princípios morais existentes separadamente da autoridade da comunidade que os retêm. Esses indivíduos consideram princípios éticos abstratos de certo e errado, e suas decisões resultam de extensões lógicas desses princípios. Eles basicamente conhecem as noções da comunidade de certo e errado, mas se guiam por sua moralidade e valores interiores para tomar uma decisão. Uma pessoa deve passar pelo primeiro nível antes de progredir para o seguinte. $(2016$, p.2)

Note-se que esses níveis são particularmente interessantes na análise do protagonista de obras de fantasia, pois não raro as regras da comunidade na qual a personagem se insere nos parecem injustas. Às vezes, questionar o status quo é a própria missão do herói.

Nesse confronto de morais e regras, não é incomum o antiherói apresentar traços de comicidade, ora por meio da paródia, ora através de um senso de humor ácido, amargurado, ocasionalmente calcado em autodepreciação. O anti-herói zomba de sua condição, de seu círculo social, das regras às quais está sujeito, da própria impotência em enfrentá-las e de sua insistência nesse sentido (guiada, é claro, por seu compasso moral divergente). Quando não zomba, é comum apresentar resignado.

Nesse contexto, ele perde a faceta de conhecedor máximo dos mistérios da narrativa, passando a ter conhecimentos limitados sobre a trama (mesmo se tiver maior entendimento do mundo sobrenatural do que as demais personagens). Sua possibilidade de 
ambivalência, em obras clássicas, converte-se em matéria para as discussões morais que invariavelmente o envolvem.

No mundo anglófono, temos alguns exemplos interessantes, em algum nível, relacionados a Tiago Boanerges, de Eric Novello. O inglês John Constantine, talvez um dos mais icônicos magos anti-heróis da fantasia urbana, precede os demais. Personagem criada como coadjuvante nas HQs da Saga do Monstro do Pântano (1983-1987), assinadas por Alan Moore, ganhou uma série própria, Hellblazer (1988-2013), roteirizada por Jamie Delano e ilustrada por John Ridgway. Como bem comentam Mattos e Sampaio,

Constantine ostentava o arquétipo típico do antiherói, sendo um personagem errante, controverso e, na maioria das vezes, politicamente incorreto, visto que seu vício em fumar já lhe rendeu inclusive um câncer no pulmão. Sempre às voltas com demônios e entidades celestiais, Hellblazer representava o looser norte-americano, destituído de família, emprego e amigos, optando por trabalhar à margem da sociedade, para salvá-la das forças sobrenaturais. (2004, p.160)

De acordo com a supracitada teoria proposta por Kohlberg, Constantine figura no nível pós-convencional de moralidade. Mesmo que suas ações possam ser vistas, em última instância, como tendendo à busca de um controverso e não muito bem delimitado "bem maior", seu entorno o transforma num pária, pois acaba prejudicando pessoas próximas, em muitos casos de maneira fatal. Não por acaso, "o episódio 1 (1988) da série Hellblazer [...] denomina-se Origens: Pecados Originais, história que mescla o horror de exorcismos, fantasmas e seres sobrenaturais a um tom de forte ironia e de críticas sociais e políticas" (GUIMARÃES, 2017, 
p.353). O exorcista Constantine sempre parece amargurado frente aos perigos enfrentados, dos quais sempre sai um pouco perdedor, mesmo vencendo-os. Assombrado pelos espíritos de outrora amigos (DELANO; RIDGWAY, 1988), aos poucos o leitor descobre que Constantine, direta ou indiretamente, causou-Ihes a morte ao enfrentar alguma entidade demoníaca.

Ao mesmo tempo, ele é astucioso o suficiente para contornar os problemas mais imediatos, deixando crises de consciência e discussões morais de lado enquanto salva pessoas ou cidades inteiras de ameaças sobrenaturais. Triunfa sobre as adversidades mais óbvias, sobre o Mal absoluto apresentado, mas se vê rechaçado por entes queridos no processo e acaba por adotar um pessimismo frente ao mundo, ao aparelho corrupto do Estado, de autoridades mágicas ou uma combinação de ambos.

Sua esperteza é tamanha que, ao longo de vários arcos, firma pactos com demônios diferentes em troca de sua alma, para conseguir resolver problemas mais imediatos, e acaba por livrar-se de ambos com a ameaça de causar uma contenda de proporções monumentais no plano sobrenatural. Vence fanáticos religiosos e até mesmo anjos de moral duvidosa, mas de modos impossíveis de caracterizar como heroicos. Por exemplo, entre os números 4 e 9 (este último intitulado $O$ celestial e o profano), ele vive um romance com Zed, moça misteriosa fugindo de seu passado. Em dado momento, vimos a saber que seu verdadeiro nome é Mary e foi destinada pela família, em conjunto com alguns religiosos e anjos cuja idoneidade é questionável, a tornar-se mãe de um novo messias. Esse destino, que a moça não aceita, lhe é forçado quando a levam de volta e realizam um tipo de procedimento ritual que a despe de sua vontade. 
Para salvá-la desse destino, Constantine, que no momento tem sangue de demônio no organismo por causa de outras aventuras, mas não lhe comunica o fato, a encontra. Desejando se despedir, Zed/Mary mantém com ele relações sexuais às escondidas. A seguir, no momento do ritual que a engravidaria do suposto messias, o anjo constata que ela está "impura", "maculada" e, por isso, ela se livra do destino. No entanto, ela se ressente de Constantine no final. Este é apenas um exemplo dos muitos recursos inortodoxos utilizados pela personagem para triunfar sobre o mal.

Hellblazer também possui forte viés noir, tanto pela ambientação quanto pelas temáticas e o tom de abordagem, com o qual Novello muito dialoga.

Outro mago anti-herói bastante representativo é o americano Harry Dresden, narrador-protagonista da série de quinze livros The Dresden Files (2000-2018), do americano Jim Butcher (1971). À semelhança de Constantine, é um mago autodeclarado habitando uma metrópole cética. Diferente deste, está sujeito a normas de uma organização superior, o White Council [Conselho Branco], que regula a utilização de magia e o tipo de informações autorizadas a serem compartilhadas com pessoas não-mágicas.

Já no primeiro volume da série Storm Front, a personagem nos é apresentada como um anti-herói, nos termos descritos por Neimneh acima. Trabalhando num escritório modesto, na maior parte do tempo considerado um charlatão, tem dificuldade de conseguir trabalho para pagar as contas. Sua maior cliente é a detetive e diretora do departamento de Investigações Especiais de Chicago e, na maior parte do tempo, também sua amiga, Karin 
Murphy. Embora ela não tenha grande conhecimento sobre a esfera do sobrenatural, sabe que algumas coisas não podem ser explicadas somente pela ciência. Nesses casos, contrata Dresden como consultor.

O fato de Dresden não poder Ihe revelar muito sobre a magia e o Conselho Branco, somado ao ceticismo de Karin, apesar de sua mente aberta, costumam atrapalhar bastante o trabalho do mago, tornando suas aventuras bastante rocambolescas, cheias de desencontros. No primeiro livro, a suspeita de misteriosos assassinatos recai justamente sobre Dresden e ele precisa contornar a justiça e uma série de outros problemas para se provar inocente e apanhar o verdadeiro culpado.

Também em Storm Front sabemos que Dresden está em maus termos com o Conselho, que o mantém vigiado para não lhe permitir usar seus poderes em desacordo com as normas. Isso por ele ter, uma década antes, matado seu mentor, que pretendia forçá-lo a seguir caminhos de magia negra. Mesmo se tratando de um crime cometido em autodefesa e isso ter ficado comprovado perante a autoridade mágica (BUTCHER, 2000, p.76-77), Dresden ainda é visto com desconfiança por ter utilizado a magia para assassinar alguém.

Um último mago anti-herói a ser mencionado é o inglês Alexander Verus, narrador-protagonista da série homônima de nove livros (2012-2018) do inglês Benedict Jacka (1980). Tanto quanto seu antecessor, Verus está em maus termos com seu respectivo Conselho e também por causa do antigo mentor. No entanto, em seu caso específico, foi ele quem buscou o afastamento por discordar da postura de uma facção poderosa, a dos dark mages 
[magos sombrios] (da qual seu mentor fazia parte), para quem a incapacidade de se defender é uma falha dos fracos a ser explorada pelos poderosos (JACKA, 2012).

Guardando semelhança tanto com Dresden quanto com Constantine, Verus também tem dificuldade de se relacionar com outras pessoas, preferindo manter-se afastado, e habita uma Londres igualmente cética quanto ao sobrenatural. Sua aprendiz e única amiga relativamente próxima é uma jovem amaldiçoada que, a princípio, não tem domínio consciente sobre seus talentos mágicos. Como Dresden, vê-se arrastado para uma trama contra sua vontade e precisa solucioná-la para manter-se em segurança e proteger sua parceira e os civis não-mágicos ameaçados pelo grande e maligno poder lutando para ser libertado.

Seus métodos são menos inortodoxos do que os de Constantine e seu status de anti-herói advém de sua relativa fraqueza frente a inimigos mais poderosos, superada pela inteligência e astúcia, e a vantagem trazida por seu talento mágico (a clarividência). Também na esteira de Constantine e Dresden, às vezes comporta-se como um trickster, enganando múltiplos oponentes e escapando deles por pouco.

Ser incompreendido parece uma característica comum a esses magos da fantasia urbana contemporânea. A incompreensão sofrida explica a amargura e o isolamento comum a esses protagonistas e atua de forma a justificar atitudes consideradas inadequadas a um herói tradicional, como, por exemplo, deixar de cumprir uma obrigação que salvaria civis em proveito próprio, caso de Tiago Boanerges. 
Cada um a seu próprio modo, eles não se conformam com a reiterada punição, vinda de todos os lados, para seus mínimos impulsos egoísticos, os quais parecem dragá-los sempre mais para o proverbial fundo do poço. Existe um constante conflito entre os eixos do dever e do querer. Nos casos de Dresden e de Verus, sentem-se impelidos pela ética e pelas circunstâncias a resolver situações das quais preferiam manter-se afastados.

Os triunfos de seu fabuloso poder não lhes tornam mais fácil, por exemplo, conseguir um trabalho honesto sempre e pagar as contas. Em geral, acabam em bares sujos ou sarjetas, lamentando seus destinos com álcool e/ ou cigarro, mesmo se de vez em quando obtêm um alívio com algum romance ou o elogio de um superior que não tem poder para reintegrá-los, mas aprecia seus esforços.

Em termos de narrativa, nas aventuras de Dresden e de Verus, as coisas parecem evidentes. Com Dresden, o "lado sujo" da sociedade figura nas múltiplas referências ao eixo dos criminosos, enquanto a autoridade (na figura da polícia) aparece, em geral, de forma euforizada, à maneira bastante superficial dos filmes hollywoodianos centrados no ponto de vista do bom policial em oposição a um vilão. Já Verus traz disforizada a alta sociedade dos dark mages que enriquecem à custa de seus poderes e de causar mal aos mais fracos, especialmente numa sequência ocorrida durante uma festa (JACKA, 2012, p.118). No todo, ambas as narrativas se mostram mais maniqueístas, mesmo que seus protagonistas antiheróis não o sejam integralmente.

Tiago Boanerges, por outro lado, não só constitui um anti-herói como se insere numa narrativa povoada de ambivalências. Todas 
as personagens ao seu redor têm algo a esconder (senão dele, do leitor), embora nem sempre seja alguma coisa ruim, contribuindo para um sentimento perene de incerteza e instabilidade, os quais, por sua vez, são reflexos e se refletem no próprio protagonista. Em outras palavras, no romance de Novello, não haveria lugar para um herói típico. Com as fronteiras entre bem e mal esfumaçadas, só um anti-herói consegue transitar de maneira verossímil.

Assim sendo, apesar de tudo o que os aproxima, cada um desses magos possui inúmeras particularidades e aqui nos interessa especificamente as do anti-herói de Libertà, a São Paulo mágica de Novello.

\section{O MAGO ANTI-HERÓI DE NOVELLO}

Tiago Boanerges, protagonista do romance Amores, Exorcismos e uma Dose de Blues, insere-se nessa recente tradição do mago anti-herói que vimos discutindo, mas apresenta particularidades oriundas de seu contexto específico.

Como Dresden e Verus, Boanerges também é renegado pelo Conselho que rege as normas de utilização da magia em seu mundo, mas, diferente dos dois primeiros, a explicação para isso se volta contra o protagonista e não contra essa grande figura incorpórea de autoridade. Onde ambos os magos anglófonos haviam, num tempo anterior à narrativa, agido em desacordo com as regras por motivos mais tarde considerados "justos" pelo enunciatário, descobrimos que o do brasileiro deixou de executar sua obrigação em proveito próprio e enfrenta as consequências disso.

Em contraponto, ele também se reaproxima do mago merlinesco, como Verus, por ser uma espécie de mentor para Julia 
Yagami, uma jovem necromante, por ele salva em momento anterior ao narrado e quem ajuda a superar traumas no presente narrativo, sendo também ajudado por ela enquanto a ensina. Nesse aspecto, assume facetas do papel do tradicional mago conselheiro, embora de maneira incompleta: onde Merlin, Gandalf e Dumbledore têm praticamente todas as respostas, ou sabem como encontrá-las, o conhecimento de Boanerges transmitido a sua aprendiz é limitado, restringindo-se à esfera do sobrenatural, oriundo de sua experiência e estudos. Ele não possui qualquer domínio sobre a narrativa, não tem como fazer os jogos de revelar e ocultar informações para o caminho a ser trilhado por Julia. Isso, é claro, se deve a seu papel na narrativa: é ele o protagonista e ela a coadjuvante.

O universo fantástico de Novello é relativamente diferente dos demais analisados aqui, pois não trabalha com o imaginário abraâmico. Nele, existem seres oníricos, pertencentes a outro plano de existência, capazes de "incorporar" em seres humanos no plano dito "material". Essa espécie de possessão em geral mantém o possuído consciente do que está havendo, para o bem ou para o mal, e pode ser tanto previamente acordada quanto uma invasão. Porém, esses oníricos não têm autorização do Conselho de Hórus para circular livremente no plano dos humanos, mesmo se "convidados" à possessão, pois os prejudicam de várias maneiras quando extrapolam as regras. Daí vem a imagem do "exorcismo", referenciando a mitologia judaico-cristã, mas dela desligada: o processo liberta o possesso da influência desses oníricos, enviando-os de volta à sua dimensão de origem e livrando a sociedade como um todo dos perigos potenciais causados por sua presença. 
Para ilustrar, um desses perigos é uma doença sexualmente transmissível, a morte negra, causada a humanos que mantêm relações sexuais com seres oníricos (através do corpo de um hospedeiro) sem antes terem comido uma fruta capaz de prevenir o contágio.

No entanto, dada a ambientação noir do romance, as coisas não são tão duais. Por exemplo, os efeitos da presença de um onírico no corpo são potencialmente afrodisíacos e/ou entorpecentes tanto para o possesso quanto para a pessoa que venha a ter relações sexuais com este, engendrando toda uma indústria clandestina para permitir a presença desses seres incorpóreos em determinados ambientes.

A irresponsabilidade de Boanerges, que vimos a conhecer logo no início do romance, em cena a ser analisada a seguir, é justamente ter se apaixonado (emocional e fisicamente) por uma musa espécie de onírico que, como suas homônimas gregas, inspira a criatividade humana, mas consome a energia vital do hospedeiro, podendo matá-lo - e deixa de exorcizá-la quando deveria, pondo em risco a vida da cantora Liz, cujo corpo ela possui, e a de todo o mundo, por deixar um onírico tão poderoso livre neste plano. Assim sendo, o individualismo hedonista do anti-herói não só o prejudica, como a terceiros.

Os embates sobrenaturais na obra de Novello possuem o mesmo relevo dos dilemas pessoais do protagonista, entrelaçados pelo fato de que o amplo universo interior da personagem altera o equilíbrio do exterior. Sua escolha individual num momento anterior à narrativa cria a problemática maior a ser enfrentada no nível coletivo. 
Boanerges não se pretende correto, ao contrário dos outros anti-heróis acima analisados; sua própria bússola moral indica o quão errônea foi sua atitude. Ainda assim, ele se deixa guiar pelo impulso lascivo (e afetivo) despertado pela musa. Nesse aspecto, talvez, retome algumas versões de Merlin, nas quais é seduzido pela Dama do Lago, Nimue (ou Viviene, como ficou conhecida a partir de reinterpretações francesas).

Desde o início, temos indícios da dubiedade de Tiago Boanerges, embora, como é ele o protagonista e o narrador se focaliza no mais das vezes em seu ponto de vista, não se suspeite de sua idoneidade. Para demonstrar como isso se dá, em nossa análise nos ateremos a uma cena específica, por crê-la muito representativa da atmosfera e do conteúdo do romance. Ela se inicia da seguinte forma: "[Tiago] iria se encontrar com o antigo supervisor pela primeira vez desde que o Conselho de Hórus o afastara há três longos anos por violar as normas em uma missão. Queria causar uma boa impressão, mostrar que estava muito bem sem o apoio deles, obrigado" (NOVELLO, 2014, p.10 - grifos nossos).

No trecho, apesar de o leitor ainda não saber ao certo quais as dimensões do poder do Conselho de Hórus e qual a realidade política dessa São Paulo alternativa, apreendemos algumas coisas: o protagonista está se encontrando com um antigo chefe, de um trabalho do qual fora afastado contra sua vontade por ter cometido um erro. Não qualquer tipo de erro: havia violado as normas. Conforme já mencionado, não estar em bons termos com o corpo de autoridade mágica parece ser uma característica comum ao mago anti-herói; Dresden não está (BUTCHER, 2000, p.23), nem Verus (JACKA, 2012, p.9). No entanto, em ambos os casos, a contenda é 
antiga - por volta de uma década ou um pouco menos - e parecenos justificada.

No caso de Boanerges, o hiato é menor ("três longos anos"), mas parece estender-se na percepção da personagem, como o uso do adjetivo "longos" dá a entender. Tal distensão temporal pode ser indício tanto de culpa e arrependimento quanto das dificuldades financeiras pelas quais andou passando sem o emprego. Como se nota, oposição entre o eixo do fantástico, tipicamente associado à figura do mago, e o extremo cotidiano das narrativas realistas, exemplificado pela necessidade de dinheiro, leva a figura a perder um pouco de sua esfera altiva - inegável nos herdeiros dos magos tradicionais, como Gandalf e Dumbledore - e a ganhar uma face humanizada.

Novello também utiliza a ambientação para trabalhar a passagem do tempo e, com isso, demonstrar a situação de seu protagonista. Numa narrativa mais insinuante do que didática, acompanhamos o olhar da personagem e percebemos seu estado passional. Por exemplo:

Era lá [na Drinqueria Blues] que Tiago costumava afogar as mágoas a cada serviço ou romance frustrado que tirasse o seu sossego. Pelo menos tinha sido assim antes de ser enxotado pelo Conselho de Hórus. Não que o dono do bar se importasse com a sua situação no trabalho, mas se importava com a falta de dinheiro, e o que foi um incentivo nas primeiras semanas logo se tornou uma conversinha na sala dos fundos para avisar que o "põe na conta" havia terminado. (NOVELLO, 2014, p.12)

Na passagem, temos indícios de um aspecto durativo do tempo, bruscamente interrompido, que em poucas palavras constrói toda 
uma relação entre Boanerges, a Drinqueria Blues e seu dono: o mago já teve diversos serviços e romances frustrados e nem todos tiraram seu sossego a ponto de precisar "afogar as mágoas"; o dono do bar o conhecia bem, provavelmente chegando a nutrir por ele certo grau de afeição, do contrário não o "incentivaria" após a perda do emprego, inclusive arcando com algum prejuízo, insinuado pela menção à "conversinha na sala dos fundos". Além disso, o termo "enxotado" usado para se referir à sua demissão do Conselho de Hórus reflete amargura e rancor, talvez até mesmo indignação. Essa ideia é especialmente interessante por construir uma protagonista complexa, com uma psique bastante humana: sabemos que ele violou alguma regra em uma missão, embora ainda não tenhamos sido informados de qual, e isso resultou na demissão. Ainda assim, o mago dá sinais de sentir-se injustiçado por seus antigos empregadores.

Toda essa ambivalência une-se a um forte apelo musical (o livro é inteiro permeado por uma trilha sonora de blues, ora referenciada através de trechos de letras de músicas, ora mencionada de passagem) e à descrição de alguns ambientes para criar uma atmosfera noir. Segundo Marilu Oliveira,

Credita-se o nome 'romance noir' aos livros de crimes editados com esse detalhe [capas pretas], enquanto outros alegam que tal se devia à atmosfera dos relatos, à paisagem sombria, noturna, à violência, com jogos de claro/escuro, levando à sensação de claustrofobia, desespero, niilismo. [...]

Mesmo que as coisas se resolvam, fica um travo amargo, como aquele deixado pela bebida e pelo cigarro na boca do private eye [detetive particular] 
que, sempre em ação, saindo de um escritório na maioria das vezes decadente, vai lidar com o provável, pois não há mais certezas, na cidade grande perigosa. Ele é um loner [solitário] que vagueia num mundo de sombras, um voyeur à espreita de crimes e criminosos.

[...] o investigador privado tem sua solidão duplicada pelo sentimento de abandono, pois, sem amigos, não tem a quem recorrer, trabalhando sozinho. Entretanto não desiste, pois é um hard boiled [durão e cínico]. (2010, p.6)

Boa parte dessas características são encontradas nas narrativas dos magos anti-heróis, todas elas também passíveis de serem lidas pela chave da literatura policial em uma hibridização com as categorias do fantástico, mas em nenhuma tanto quanto no romance de Novello. Não só pelo viés investigativo quanto pelo clima noturno e por vezes claustrofóbico, aliado à solidão e à já mencionada amargura.

Para melhor exemplificar, voltamos ao cenário onde ocorre o primeiro diálogo entre o protagonista e seu outrora supervisor, que se vê praticamente forçado a recontratá-lo para acompanhar um novo caso, derivado dos acontecimentos que culminaram na demissão de Boanerges, pois ninguém mais dispõe de suas especificidades.

Tiago Boanerges parou um instante para verificar se estava no lugar certo. Antes discreta, a porta agora contava com um letreiro luminoso. Um brutamonte com implante no olho esquerdo, uma espécie de monóculo de lente vermelha, repousava em um banco com a cara sonolenta. De terno preto completo, parecia um segurança engomadinho de shopping, mas o cão de três cabeças estampado em seu uniforme indicava um trabalho diferente. 
[...] Fazia pelo menos um ano que não colocava os pés na Drinqueria. $\mathrm{O}$ vigilante e o letreiro não foram as únicas mudanças do período de reforma. O ambiente ganhara nova demão de tinta, com luminárias e contornos coloridos para o bar. As pilastras contavam agora com fotos e notícias sobre o mundo do blues misturadas a imagens da década de 1950. As cadeiras e os sofás recostados à parede tinham recebido um estofado preto e, mesmo em um dia de baixo movimento como aquele, havia mais de um funcionário disponível no salão, uma raridade nos velhos tempos. Pelo visto, cortar frequentadores sem grana trouxe bons resultados. (NOVELLO, 2014, p.12-13)

Nota-se já de saída o mesmo tom amargurado que permeia todo este início de narrativa. A descrição do ambiente contribui para o clima noir e reforça a análise anterior da relação estreita entre o protagonista e o bar. O hiato de um ano, apesar de consideravelmente menor do que o tempo desde a demissão de Boanerges, foi suficiente para alterar consideravelmente o lugar, e para melhor. Através dos olhos do protagonista, contrastando o passado e o presente, vemos um outrora bar decadente prosperar, enquanto a vida do observador piorou em muitos aspectos e ficou estagnada em outros tantos.

Não é forçoso presumir que o mago se sentisse em casa anteriormente e, nessa Drinqueria mudada, sinta-se deslocado. "Segurança engomadinho de shopping" possui um tom pejorativo, enquanto, no final da citação a menção aos "velhos tempos", costumeiramente euforizada, é seguida da crua constatação: "Pelo visto, cortar frequentadores sem grana trouxe bons resultados". Boanerges sabe que as mudanças efetivadas sinalizam um progresso, 
porém, como tal progresso não se reflete em sua própria vida, marca-se a sensação de estranheza e falta de familiaridade, eivada de amargura e até certa inveja. Onde antes havia esperado encontrar um território conhecido, vê outro sinal de sua ruína pessoal.

Porém, o encontro com o antigo supervisor, Marcos Sardenha, é uma oportunidade de reaver alguma coisa de sua vida anterior. Ocorre um conflito entre seu orgulho ferido e a esperança que não quer alimentar, reforçado pelo embate entre a consciência de ter agido errado e o senso - orgulhoso - de haver sido injustiçado por seus superiores. Até então, o leitor ainda não foi informado de qual foi sua falha e, portanto, não tem como julgar o caso; apenas acompanha o progresso da discussão pelos sentimentos e digressões do protagonista.

O reencontro transcorre com uma falsa civilidade, a princípio, e uma hostilidade refreada de ambas as partes:

"Pelo que pesquisei antes de vir, esperava encontrálo debilitado", disse Marcos Sardenha, rompendo o silêncio. Era um agente de campo bem-sucedido que havia alcançado em poucos anos o cargo de supervisor e não demoraria muito a se tornar o chefe da divisão. [...] Tiago não conseguiu disfarçar o desagrado. Pensou por um instante se seria esse - motivo da escolha da Drinqueria Blues como local de conversa, evitar que precisasse se deslocar para longe de casa, arrastando seus problemas e enfermidades. Um toque de piedade para disfarçar o desinteresse pós-julgamento.

"Me cuido como posso", respondeu, apesar de saber aonde ele queria chegar. Sentir-se bem diante do homem que o havia comunicado de sua expulsão estava sendo uma tarefa mais complicada do que previra. 
"Depois que deixou o Conselho, ouvi boatos de que sua saúde não andava bem."

"Vamos deixar os eufemismos de lado. Eu não saí porque quis, fui afastado por vocês, e conheço os boatos. Depender do Entremundos para sobreviver pode não ter me deixado rico, mas fique certo de que estou bem informado."

Apesar de não ter ideia do motivo de estar aqui, pensou. E pelo sorriso de canto de rosto de Marcos, tinham pensado o mesmo.

"A maioria dos magos não assumiria em voz alta suas atividades na cidade entre os reflexos."

"Como bem sabe, não sou homem de esconder meus atos."

"O que sempre fez de você um de meus favoritos. Apenas se acalme, não vim aqui para discutir. Muito pelo contrário, quero reparar erros antigos que foram cometidos contra a minha vontade", disse ele, repousando o charuto no cinzeiro. (NOVELLO, 2014, p.14-15)

Observamos um intenso jogo entre o dito e o não-dito. Ambos conhecem algo que ainda não é revelado ao leitor, mas a tensão permeando a interação se faz notar. A pausa ao final do trecho, que abrirá espaço para as digressões do protagonista, serve para pontuar esse clima, além de surpreender pelo teor da fala do supervisor. Ele, afinal, se exime da "culpa" da demissão do mago exorcista e abre uma deixa com um tom amigável. Ao enunciatário são deixados fragmentos de informações: Tiago Boanerges possui problemas de conhecimento público, enfrentou um julgamento, é vítima de boatos sobre sua saúde, provém o próprio sustento com atividades provavelmente ilícitas num lugar chamado Entremundos. 
Assinalando novamente a ambientação noir do romance, justamente a confissão dessas atividades é o que conquista a declarada benevolência do interlocutor, mostrada com "o que sempre fez de você um de meus favoritos". A alegada transparência de Boanerges, quer aja em acordo quer em desacordo com as normas do Conselho, torna-o, de certa forma, confiável. Isso, é claro, está dito por Sardenha, cujos verdadeiros propósitos nem o protagonista nem o enunciatário conhecem, de modo a suscitar uma dúvida: a trégua é de fato fruto de um arrependimento ou é um artifício?

O parágrafo seguinte à pausa explicita o conflito interno do protagonista:

À espera de uma pausa estratégica, a garçonete se aproximou e deixou o copo de Bourbon. Tiago balbuciou um obrigado e agradeceu em silêncio pela interrupção. Fechou os olhos, se deliciou com o aroma adocicado e demorou a dar o primeiro gole. Sentiu com satisfação o calor voltar ao corpo e repassou na cabeça o motivo de estar ali engolindo o orgulho, a esperança carregada no fundo do bolso. Se havia uma chance de voltar ao Conselho de Hórus, não a desperdiçaria. (NOVELLO, 2014, p.15)

No fim, Tiago Boanerges é um sujeito passional, cujo estado se mantém em suspense no frágil equilíbrio entre duas paixões igualmente norteadoras de suas ações: o orgulho e a esperança. Apesar de se tratar de um diálogo num bar, cena bem corriqueira em vários tipos de romance, sobretudo os de ambientação noir, e de ainda não sabermos exatamente por que o representante do Conselho de Hórus procurou o protagonista - nem mesmo o que 
gerou tamanho impasse - a sensação de tensão, de haver muito em jogo, acompanha todo o episódio.

Mais à frente, revela-se que o personagem Marcos Sardenha desejava de fato inteirar-se do estado de saúde de Boanerges, quando vimos a saber quais eram os rumores acerca do mago exorcista. Embora o supervisor não os mencione de modo direto, provoca uma forte reação em seu interlocutor, como trecho abaixo:

"Está até mais gordinho do que da última vez que nos vimos."

"Sem gozação com a minha cara."

"E por que acha que estou brincando? Saí do escritório imaginando o pior. Achei que encontraria um exorcista cadavérico, à beira da morte. Vê-lo assim é uma grata surpresa."

As memórias sinestésicas voltaram com força. A sensação de coceira enquanto tentava dormir, os órgãos dilatados disputando espaço uns com os outros. O mundo se turvou ao redor de Tiago, borrando a imagem do supervisor como um esguicho de aguarrás numa tela impressionista. Por pouco, não apagou na frente dele. (NOVELLO, 2014, p.16)

Esse parágrafo será explicado em fragmentos ao longo da narrativa, mas já na página seguinte, quando Boanerges vai ao banheiro para se recompor, fica claro que os boatos referidos desde o início do diálogo entre os dois aludem à possibilidade de Boanerges haver contraído a morte negra. De fato, foi esse o caso, como as "memórias sinestésicas" sugerem e as digressões posteriores do mago confirmam. Sardenha, ao encontrá-lo saudável julga "uma grata surpresa" porque a doença, fatal, não tem cura 
e, assim sendo, leva-o a crer que os boatos antes referidos não tinham fundamento. No entanto, Boanerges só sobreviveu por ter travado uma espécie de pacto com um ser onírico, que, em troca, pediu seu coração (literalmente), substituindo-o por um feito de fumaça, a "matéria" de alguns dos seres desse plano. Os termos, condições e consequências dessa troca não são todos explicitados; apenas permitem ao protagonista transitar com alguma altivez e dignidade, apesar da vergonha pública de seu fracasso.

Fazer um pacto para se livrar de um mal imediato não é uma novidade de Novello; remete-nos de volta a Constantine e também a Dresden, em menor escala, cujas barganhas às vezes são custosas. Por exemplo, em troca do favor de um demônio, ele lhe diz um de seus nomes. No universo da série The Dresden Files, saber o nome completo de qualquer ser segundo pronunciado por seu dono é o modo de asseverar poder sobre ele, possibilitando compeli-lo a agir contra a própria vontade (recurso recorrente em diversas obras de fantasia, como no recente Ciclo da Herança, de Christopher Paolini).

Voltando à obra em análise, o clima noir não abandona a conversa por um momento sequer e nas pausas do diálogo isso se manifesta de maneira mais explícita. Por exemplo: "Marcos bateu a cinza do charuto e tragou. Soprou a fumaça para o lado, fingindo se importar [que o charuto incomodava Boanerges]. Seus olhos se demoraram mais um tempo na mesa dos fundos antes de reencontrarem os de Tiago. Mesmo com a aura de autoridade recomposta, deixava transparecer alguma tensão" (NOVELLO, 2014, p.18). A postura de autoridade do supervisor e a série de coisas não ditas que se entrevê na referida "tensão", logo após a reação do mago a seu passado com a morte negra, prolonga a interação 
entre os dois no bar, com a música tocando, e acumula-se ao efeito de emergência. O fato de Sardenha estar obviamente contrafeito em contatar Boanerges, mas a evidente necessidade de fazê-lo, contribui para aumentar a curiosidade do protagonista e, com isso, a do enunciatário.

O charuto de Sardenha empresta à cena algo mais da plasticidade noir, por conter, a um só tempo, a aura de determinada autoridade aristocrática de outros tempos - ao mesmo tempo, passível de ser vista como anacrônica e decadente - e certa alusão ao submundo dos chefões do crime, também remetendo a outra época, o que bem condiz com o blues e o os anos 1950 evocados pela ambientação do bar. Também ele é uma personagem dúbia, mas não mal-intencionada, como ao final descobriremos.

Após toda a construção da tensão, a cena enfim desemboca na revelação do motivo de o supervisor haver procurado Boanerges: a musa voltou. O julgamento aludido de passagem foi o enfrentado por Boanerges após ter escolhido não a exorcizar da cantora Liz, mantendo-a no plano material, o que culminou com a morte de um civil. Apaixonado pela musa, manteve com ela um relacionamento, do qual resultou sua contração da morte negra.

Diante da notícia do retorno da musa,

Tiago ficou sem ação. Estava pasmo e, de certo modo, feliz. O motivo de sua desgraça tinha voltado e ele estava sorrindo na frente do supervisor que Ihe expulsara por falhar diante dela. Tratou de esconder os dentes e franzir a testa. Conforme o bom senso retornou, a simulação deu lugar a um sentimento real. A musa era perigosa e ele sabia disso melhor do que ninguém, por mais que seu 
coração inexistente dissesse o inverso (NOVELLO, 2014, p.18-19).

O clássico conflito entre razão e emoção apresenta-se. Por um lado, o mago tem consciência de, por causa da entidade, ter perdido o emprego, quase sofrido uma morte dolorosa, posto em risco a segurança de Liz e dos humanos em geral. Por outro, uma parte de si acredita ter sido amado pela musa e, isso associado à lembrança do prazer físico inigualado pelas experiências meramente humanas, alimenta uma esperança de fruição que ele sabe ser inadequada e, mesmo se possível, não prolongável. Além do embate de cunho individual, outro se sobrepõe, e este sim é externalizado por Boanerges: a oportunidade de redenção, de provar-se digno de voltar às boas graças do Conselho de Hórus - e, por consequência, resolver sua vida financeira.

O trabalho ofertado não é exorcizar a musa - nisso Boanerges já falhou antes e seu supervisor não deseja lhe dar a oportunidade de fazê-lo novamente (NOVELLO, 2014, p.20) —, mas apenas monitorar Liz para o caso de a entidade tentar possuí-la outra vez. Isso suscita novos sentimentos conflitantes, segundo se pode depreender do trecho abaixo:

Se não conseguia resistir ao prazer de um gole de Bourbon, como se manteria longe da musa? Da sua musa! Se tivesse um mínimo de bom senso, diria não e iria embora. Aquele problema não mais Ihe pertencia. [...] Tiago reavaliou a situação. Por mais que houvesse agido de forma errada com Liz no passado, era de fato a melhor opção para monitorá-la. Havia acompanhado todos os estágios de possessão, conseguiria identificá-los de olhos fechados dessa vez. E mais importante: devia isso 
a ela. Aproveitaria a chance para se redimir e a protegeria caso a musa fizesse uma nova investida. Com sorte, seria apenas uma visita de rotina, uma retomada de convivência. Marcos estava certo, eles mereciam uma segunda chance. (NOVELLO, 2014, p.21-22)

O resto da narrativa será permeado por suas tentativas de reaproximação, investigações paralelas que deságuam na chegada da musa e sua vingança por ter sido banida, e a superação das capacidades tanto afetivas quanto mágicas de Boanerges. Com isso, na trama principal, Tiago é anti-herói, principalmente pela sua intensa humanização e vulnerabilidade diante da exploração de sua humanidade (física e psicológica) pelo ser onírico referido como "sua musa". A humanidade figura como fragilidade frente ao poder onírico da musa.

O processo de sua redenção também é um desvelar das fragilidades da instituição do Conselho de Hórus, do equilíbrio delicado com o Entremundos (espécie de entrelugar ou não-lugar, onde diferentes realidades se acessam), além de um enaltecimento de sua humanidade. A mesma vulnerabilidade emocional que nubla seu julgamento no episódio de seu fracasso o leva a enfrentar e vencer a musa e, num final bastante agridoce, a compreender que resquícios dela ainda habitavam Liz, com quem havia conseguido voltar a estabelecer um novo relacionamento e a exorcizar a entidade incorpórea de vez.

A vitória que lhe devolve o trabalho (NOVELLO, 2014, p.329) também o destrói psicologicamente. É interessante notar como o conflito se resolve integralmente na psique do protagonista: após um embate de proporções grandiosas, aos moldes do modo 
narrativo da fantasia, no qual enfim exorciza a musa (p.315-327), Boanerges parece ter alcançado um estado de graça com Liz, no capítulo final bastante doméstico com ares de epílogo (p.328-331).

Num contexto romantizado, ele percebe que a amante ainda guarda parte da musa em si. Ela tenta seduzi-lo de modo sutil, mais afetivo do que sexual, e ele, sempre apontando a dificuldade de não se deixar levar por suas próprias vontades, a exorciza. O embate entre o dever e o querer, entre egoísmo e altruísmo, acontece somente na esfera íntima da personagem; não há nova batalha.

Nesse momento, a solução é um prolongamento da dor e da frustração. No caso de Boanerges, um final vitorioso constitui uma impossibilidade, pois o sucesso em um aspecto determina, obrigatoriamente, o fracasso em outro. O moralmente correto e sua vontade individual se contrapõem e é seu compasso moral que decide a disputa. Ainda assim, em algum nível sua vontade é bipartida, visto existir o desejo, prevalecente, de fazer o certo, ou a conclusão teria sido outra.

Com isso, fica marcado o quanto, apesar de encontrar identidade com outros magos anti-heróis do gênero, o protagonista de Novello apresenta-se de modo muito particular, numa narrativa na qual suas peripécias são fruto e motor da subjetividade do sujeito em relação a si mesmo e ao mundo, misturando desordens de natureza pessoal e elevando-as ao nível das grandes batalhas épicas da fantasia contemporânea. 


\section{REFERÊNCIAS}

BURNETT, Hunter A. (2016). An exploration of the anti-hero from past in two cultures: American and Japanese. San Marcos (Texas): Texas State University (Honors Thesis). In https://digital.library.txstate.edu/bitstream/ handle/10877/6079/BurnettHunter.pdf?sequence=1 Acesso em 18.Mai.2018.

BUTCHER, Jim (2000). Storm Front (The Dresden Files - Book 1). Nova York: Roc Books.

CAMPBELL, Joseph. O herói de mil faces. Adail Ubirajara Sobral (Trad.). São Paulo: Pensamento.

CAMPOS, Brielle (2016). Hybrid Genre and Character Representation: Noir, Fantasy, and Fantasy Noir in Constantine, Pushing Daisies, and The Dresden Files. Youngstown (Ohio): Youngstown State University, (Dissertação). In https:// etd.ohiolink.edu/!etd.send_file?accession=ysu1464790300\&disposition=inline Acesso em 19.Mai.2018.

DELLANO, Jamie; RIDGWAY, John (1988). A feast of friends. Nova York: Vertigo. GINZBURG, C. (2012). História Noturna: Decifrando o Sabá. N. Moulin (Trad.). São Paulo: Cia de Bolso.

GUIMARÃES, Denise Azevedo Duarte (2017). "A luciferian transposition of Hellblazer/Constantine: From comic book to film". Fronteiras, 19(3), 351362. In http://www.revistas.unisinos.br/index.php/fronteiras/article/view/ fem.2017.193.07/6362Acesso em 19.Mai.2018.

JACKA. Benedict (2012). Fated (Alex Verus - Book 1). Londres: Hachette UK.

KADiROĞLU, Murat (2012). "A Genealogy of Anti-hero". Ankara University DTCF Journal (Dil ve Tarih-Coğrafya Fakültesi Dergisi), 52, 1-18. In https:// www.academia.edu/28461479/A_GENEALOGY_OF_ANTIHERO Acesso em 18.Mai.2018.

MATANGRANO, Bruno Anselmi; TAVARES, Enéias (2018). Fantástico brasileiro: o insólito literário do Romantismo ao Fantasismo. Curitiba: Arte e Letra.

MATTOS, Leonardo Martinelli de Campos; SAMPAIO, Rafael Cardoso (2004). A evolução do mito do herói dos quadrinhos. Juiz de Fora:UFJF; FACOM, (Monografia). In http://www.ufjf.br/facom/files/2013/04/LeonardoMattoseRafaelSampaio. pdf Acesso em 02.Jun.2018. 
NEIMNEH, Shadi (2013). "The Anti-Hero in Modernist Fiction: From Irony to Cultural Renewal". Mosaic, 46(4), 75-90. In https://pdfs.semanticscholar.org/ c382/4f92d090386395446d992f608b0ebecfc2f3.pdf Acesso em 19.Mai.2018.

NOVELLO, Eric (2014). Exorcismos, Amores e uma Dose de Blues. Belo Horizonte: Gutenberg.

OLIVEIRA, Marilu Martens (2010). "Sobre crimes, mulheres fatais e investigadores: do romance noir ao filme neo-noir, um longo percurso". Diálogo e Interação, 2(10). Cornélio Procópio (PR): Faculdade Cristo Rei, p.1-11. In http:// www.faccrei.edu.br/wp-content/uploads/2016/10/diartigos36.pdf Acesso em 02.Jun.2018.

PEREIRA, Rita de Cássia Mendes; MATIAS, Kamilla Dantas (2013). "De mago, profeta e louco... Merlin na historiografia e na literatura dos séculos XII e XIII". Brathair, XIII (2), 63-82. In http://ppg.revistas.uema.br/index.php/brathair/ article/view/843/696 Acesso em 16.Mai.2018.

REDONDO, Paloma Galán (2007). "Los orígenes merlinescos de Gandalf". In: 1616: Anuario de la Sociedad Española de Literatura General y Comparada, XII. Alicante: Biblioteca Virtual Miguel de Cervantes, p.149-160. In http://www. cervantesvirtual.com/obra/los-orgenes-merlinescos-de-gandalf-0/. Acesso em 17.Mai.2018.

RINALDI, Azzurra (2016). "A sobrevida de Merlin: da Idade Média à contemporaneidade". Literatura em Debate, 10(19), 4-17. In http://revistas. fw.uri.br/index.php/literaturaemdebate/article/view/2491/2192 Acesso em 16.Mai.2018.

SPRENGER, Jacob; KRAMER, Heinrich (2011). The Hammer of Witches [Malleus Maleficarum]. Christopher S. Mackay (Trad.). Cambridge: Cambridge University Press.

STAINLE, Stéfano (2016). Gandalf: a linha na agulha de Tolkien. Araraquara (SP): Universidade Estadual Paulista Júlio Mesquisa Filho (UNESP), (Dissertação). In https://alsafi.ead.unesp.br/bitstream/handle/11449/141473/stainle_e_me_ arafcl.pdf?sequence=3\&isAllowed=y Acesso em 19.Mai.2018.

TOLKIEN, J.R.R. (2001). O Senhor dos Anéis. Lenita Esteves (Trad.). São Paulo: Martins Fontes. 